\title{
Microparticles as immune regulators in infectious disease - an opinion
}

\section{Zheng Lung Ling, Valery Combes, Georges E. Grau* and Nicholas J. C. King*}

Discipline of Pathology, Bosch Institute, School of Medical Sciences, Sydney Medical School, University of Sydney, Sydney, NSW, Australia

Edited by:

Stipan Jonjic, University of Rijeka,

Croatia

\section{Reviewed by:}

Joanne Trgovcich, The Ohio State

University, USA

Angel Porgador, Ben-Gurion

University of the Negev, Israel

Mirko Trilling,

Heinrich-Heine-University Düsseldorf,

Germany

\section{${ }^{*}$ Correspondence:}

Georges E. Grau and Nicholas J. C.

King, Discipline of Pathology,

University of Sydney, Blackburn

Building, D06, Sydney, NSW 2006,

Australia.

e-mail: georges.grau@sydney.edu.au; nickk@pathology.usyd.edu.au
Despite their clear relationship to immunology, few existing studies have examined the potential role of microparticles (MP) in infectious disease. MP have a different size range from exosomes and apoptotic bodies, with which they are often grouped and arise by different mechanisms in association with inflammatory cytokine action or stress on the source cell. Infection with pathogens usually leads to the expression of a range of inflammatory cytokines and chemokines, as well as significant stress in both infected and uninfected cells. It is thus reasonable to infer that infection-associated inflammation also leads to MP production. MP are produced by most of the major cell types in the immune system, and appear to be involved at both innate and adaptive levels, potentially serving different functions in each. Thus, they do not appear to have a universal function; instead their functions are source- or stimulus-dependent, although likely to be primarily either pro- or anti-inflammatory. We argue that in infectious diseases, MP may be able to deliver antigen, derived from the biological cargo acquired from their cells of origin, to antigen-presenting cells. Another potential benefit of MP would be to transfer and/or disseminate phenotype and function to target cells. However, MP may also potentially be manipulated, particularly by intracellular pathogens, for survival advantage.

\section{INTRODUCTION}

The paradigm of intercellular cell signaling mechanisms has until recently been assumed to be limited to direct cell-cell contact and via local soluble factor release. However, there has been increasing interest in the role of plasma membrane-derived small lipid/protein vesicles in cell-cell communication in the last decade. Microparticles (MP) are one such type of vesicles gaining more recognition as their biological roles are being explored. Although there is no standardized terminology for these small extracellular vesicles, the term, microparticle, usually refers to a subset of extracellular, cell membrane-derived vesicles ranging from 0.1 to $1 \mu \mathrm{m}$ in diameter, shed directly from the plasma membrane through the process of ectocytosis (Gasser and Schifferli, 2004; Cocucci et al., 2009; Pap et al., 2009). MP are also referred to as "microvesicles" or "ectosomes," depending on the context of the study. Although MP are shed from steady-state cells, elevated levels are observed in actively proliferating cells and cells activated by a wide range of stimuli, from mitogens and inflammatory mediators, to antigenically foreign compounds, such as pathogen components, as well as various other stress-inducing challenges in both in vitro and in vivo models (Ratajczak et al., 2006; Ardoin et al., 2007). In vivo, MP are most commonly found in blood, however, they are also observed in other bodily fluids, such as synovial fluid (Berckmans et al., 2005; Distler et al., 2005b) and urine (Smalley et al., 2008).

Microparticles are often compared with exosomes and apoptotic bodies (Table 1), however, while superficial structural similarities exist between them, both the mechanism of MP formation and their subsequent composition are fundamentally different (Théry et al., 2009; Mause and Weber, 2010; György et al., 2011). MP shedding is a multi-enzyme-regulated process. Under normal conditions, the asymmetric composition of the plasma membrane is maintained by three principal translocase enzyme families of flippases, floppases, and scramblases, which actively maintain phosphatidylcholine (PC) and sphingomyelin (SM) on the external leaf, while phosphatidylserine (PS) and phosphatidylethanolamine (PE) are kept on the internal leaf. On cellular activation, these enzymes are inhibited following an influx of $\mathrm{Ca}^{2+}$ into the cytoplasm, and consequently the normal phospholipid asymmetry is disrupted (Coltel et al., 2006; Piccin et al., 2007; Pap et al., 2009). This is accompanied by the loss of actinspectrin anchorages and the degradation of actin filaments by calpain. The disruption of the cytoskeleton allows the plasma membrane to protrude outward. These protrusions are pinched off as individual MP in a Rho-associated kinase I (ROCK-I)dependent manner from the cell membrane, with PS and PE exposed on the outer surfaces. In contrast, exosomes fall into the $50-100 \mathrm{~nm}$ range and are formed by inward budding into the endosomal lumen of small intra-luminal vesicles (ILV) that aggregate to become multivesicular bodies (MVB). MVB subsequently fuse with the plasma membrane to release the ILV into the extracellular space as exosomes (Théry et al., 2009). Exosomes are enriched in CD63, and major histocompatibility complex (MHC) I and II molecules, but tend to have low levels of PS and procoagulation factors on the surface (Denzer et al., 2000; Théry et al., 2009; Mause and Weber, 2010; György et al., 2011). Apoptotic bodies, yet another type of subcellular vesicle, are much larger 
Table 1 | Comparison between microparticles, exosomes, and apoptotic bodies.

\begin{tabular}{|c|c|c|c|}
\hline & Microparticles & Exosomes & Apoptotic bodies \\
\hline Size & $100-1000 \mathrm{~nm}$ & $50-100 \mathrm{~nm}$ & $\begin{array}{l}\text { 1000-4000 nm (Théry et al., 2009; Mause and } \\
\text { Weber, 2010; György et al., 2011) }\end{array}$ \\
\hline Markers & $\begin{array}{l}\text { Tissue factor (De Rop et al., 2011; Zwicker et al., } \\
\text { 2011), cell surface markers of cell origin, PS }\end{array}$ & $\begin{array}{l}\text { CD63, CD81, CD9, LAMP1 high } \\
\text { MHC-I/II (Denzer et al., 2000) }\end{array}$ & $\begin{array}{l}\text { PS, genomic DNA, histones (Mause and Weber, } \\
\text { 2010) }\end{array}$ \\
\hline
\end{tabular}

$(1-4 \mu \mathrm{m})$ and are essentially fragments of cells produced in late stage apoptosis (Table $\mathbf{1}$ ).

The process by which MP are produced results in their possessing many of the characteristics of the cell from which they originated. This includes many of the surface molecules, such as integrins, receptor ligands, co-stimulatory molecules, as well as cytoplasmic contents, such as activated signaling molecules and even genetic materials e.g., mRNA (Baj-Krzyworzeka et al., 2006; Aliotta et al., 2010) and miRNA (Yuan et al., 2009). MP either attach and fuse to their target cell (Del Conde et al., 2005), or are internalized and processed by pinocytic or phagocytic mechanisms (Dasgupta et al., 2009; Faille et al., 2009; Abdel-Monem et al., 2010). Since MP carry biological molecules from their cells of origin, they may induce associated responses in their target cells, depending on the source of MP, the cell type on which they act and the route by which they are incorporated.

Given that MP are produced in response to many stress conditions and are involved in several immunological processes, it seems likely that MP are involved in the regulation of the immune response against invading pathogens, however, their potential role in infectious diseases has not been extensively studied. This review aims to consolidate current evidence on their biological role and venture opinion on their potential impact in infectious disease.

\section{MP IN INFLAMMATORY CONDITIONS}

One of the hallmarks of bacterial, viral, fungal, or parasitic infection is the formation of an inflammatory milieu around infected or affected cells. Pathogen-associated molecular pattern (PAMP) recognition receptors (PRR), such as Toll-like receptors, certain classes of RNA helicases, like the retinoic acid inducible gene-I (RIG-I), and NOD-like receptors (NLR), specifically detect components of the invading pathogen and trigger a cascade of intracellular signaling events that lead to the activation of transcription to initiate the first wave of innate immune responses (Creagh and O'Neill, 2006; Seth et al., 2006). Whether the initial detection of the pathogen alone can induce MP shedding is unclear. However, endotoxins, produced by bacteria during infection, or the sheer load of replicating intracellular virus would undoubtedly cause stress in affected cells. Indeed, generation of MP may be closely associated with the initiation of apoptosis and necrosis (Ardoin et al., 2007). Whether stress-inducible proteins, such as hypoxia-inducible factor $1 \alpha$ (HIF-1 $\alpha$ ), heat-shock factor (HSF-1), heat-shock protein (Hsp) family, nuclear factor $\kappa \mathrm{B}(\mathrm{NF}-\kappa \mathrm{B})$, Jun NH2-terminal kinase (JNK), and p53 (Ohiro et al., 2003; Razorenova et al., 2005; Thompson and Locarnini, 2007; Zinkernagel et al., 2007; De Maio, 2011; Li et al., 2011; Rawat and Mitra, 2011; Zhang et al., 2011) and MHC class I polypeptide-related sequence A and B (MICA, MICB; Stern-Ginossar and Mandelboim, 2009) are involved, remains to be determined. Nevertheless, a broad array of pro-inflammatory cytokines, such as tumor necrosis factor (TNF), interleukin-1 (IL-1), IL-6, and type 1 interferons (IFN-I) are produced in response to infection (Medzhitov and Horng, 2009), and many of these induce MP shedding in the absence of infection (Combes et al., 1999; Sheremata et al., 2006; Penet et al., 2008). Not surprisingly, therefore, both stimulation in vitro with lipopolysaccharide (LPS; Aharon et al., 2008; Bernimoulin et al., 2009) and intravenous injection of bacterial endotoxin in vivo (Zubairova et al., 2006; Wang et al., 2009) induce MP shedding. Furthermore, elevated blood MP levels are also observed in septic patients (Nieuwland et al., 2000; Mostefai et al., 2008), in human immunodeficiency virus (HIV) patients (Aupeix et al., 1997) and Ebola Virus-infected macaques (Geisbert et al., 2003), as well as malaria patients and Plasmodium-inoculated laboratory animals (Combes et al., 2004, 2005; Penet et al., 2008; Couper et al., 2010; Pankoui Mfonkeu et al., 2010). Thus elevated circulating MP are associated with systemic infection by a range of organisms.

Many activated immune cells not necessarily infected by pathogens, such as monocytes, macrophages, dendritic cells (DC), and lymphocytes, produce MP when activated by relevant stimuli. MP have been shown to be produced by monocytes and macrophages stimulated with A23187 (Cerri et al., 2006), LPS (Satta et al., 1994; Obregon et al., 2006; Aharon et al., 2008), and starvation (Aharon et al., 2008), by DC stimulated with LPS (Obregon et al., 2006, 2009), by T cells stimulated with agonistic CD3 antibodies, Fas ligand, heat, actinomycin-D, staurosporine, PHA, PMA (Scanu et al., 2008), and by neutrophils stimulated with fMLP and C5a (Gasser and Schifferli, 2004). In addition, MP are produced by cells isolated from patients with autoimmune disease, such as diabetes (Martin et al., 2004), as well as vascular disease (Tesse et al., 2005). The wide variety of possible stimuli producing MP in the absence of infection makes it difficult to predict pathways leading to MP production in infectious disease, or predict 
their function in this context and few experimental models utilize infectious pathogens. Nevertheless, these studies provide valuable clues to what possible responses might occur in infection.

\section{REGULATION OF IMMUNE RESPONSES}

As mentioned above, elevated blood MP levels have been reported in models of sepsis, viral infection, and cerebral malaria. Because of the generalized inflammatory conditions that such events generally create, it seems reasonable to propose this would be the case for most, if not all infections accompanied by significant hematogenous spread, i.e., during parasitemia, bacteremia, viremia or fungemia. Furthermore, due to the propensity of MP to carry contents derived from their cells of origin, it is likely that they contain antigens, either present or induced in infected cells. Plasmodium parasite antigens were detected in the MP purified from the plasma of infected animals (Couper et al., 2010). This is unlikely to be unique to parasitic infections, as infecting viruses inevitably become an integral part of the cell, inducing a range of virus-specified proteins crucial for their replication and these could become incorporated into the MP contents, either specifically or non-specifically. Thus, MP could remotely convey viral antigens via the blood stream to professional antigenpresenting cells (APC), such as macrophages and DC residing centrally in the spleen and liver without the necessity for their direct interaction with infected cells. Both organs normally have high throughputs from the systemic circulation, increasing the likelihood that MP will interact with APC. From a host point of view, this maintains a desirable separation between the peripheral site of infection and the site of immune induction. Additionally, TNF-stimulated, endothelial cell-derived MP have the capacity to induce activation and maturation of plasmacytoid DC, although not conventional DC (Angelot et al., 2009). Together, such remote interactions could increase the probability of detecting infection early, enabling prompt initiation of innate and adaptive responses by APC responding to MP in the blood. Indeed, it has been shown that MP produced by Mycobacterium-infected macrophages were able to activate and present antigen to naive T cells (Ramachandra et al., 2010), thus obviating the necessity for direct APC and T cell contact to generate a $\mathrm{T}$ cell response. In these experiments, MP were better at inducing $\mathrm{T}$ cell proliferation than exosomes. The study by Couper et al. (2010) also demonstrated the activation of bone marrow-derived macrophages, with upregulation of CD40 and TNF expression. This raises the further possibility that MP may facilitate the mobilization of subsets recruited from the bone marrow during infection (King et al., 2007; Getts et al., 2008).

As well as accepting MP by fusion, DC also produce MP following activation. LPS-induced MP from DC can transfer antigen to recipient DC, which can present this to T cells (Obregon et al., 2006, 2009; Pizzirani et al., 2007). Other cellular membrane function can be transferred by MP from activated to naïve $\mathrm{T}$ cells via the tetraspanin, CD81, important for adhesion and lymphocyte maturation (Fritzsching et al., 2002; Quast et al., 2011). Furthermore, $\mathrm{CD}_{154^{+}}$platelet-derived MP introduced into CD154-/mice triggers $\mathrm{CD} 4 \mathrm{~T}$ cell-dependent production of antigen-specific IgG and germinal center formation, suggesting that with the right surface molecules MP can fully activate the adaptive immune response (Sprague et al., 2008). Indeed, MP transfer could explain the rapid exchange of T cell receptors (TCR) observed in the early stages of $\mathrm{T}$ cell activation to expand antigen-specific $\mathrm{T}$ cell clones (Chaudhri et al., 2009). Irrespective, it seems likely that MP containing pathogen antigens along with the necessary co-stimulatory molecules can activate $\mathrm{T}$ cells, bypassing cell-cell contact, thus enabling a wider, more efficient initiation, amplification and/or modulation of early adaptive immune responses.

Microparticles may also contain pro-inflammatory cytokines, such as IL-1 $\beta$, providing an alternative or additional pathway for cytokine secretion into the extracellular space to modulate local cytokine/chemokine signaling (Mackenzie et al., 2001; Pizzirani et al., 2007). Depending on their mode of manufacture and cellular release, it seems highly likely that other cytokines/chemokines, may make use of this pathway (Garcia et al., 2005; Dean et al., 2009). Certainly, T cell-derived MP have been shown to activate monocytes (Distler et al., 2005a; Huber et al., 2007; Scanu et al., 2008) and monocytes activated with MP from PHA- or PMA-stimulated blood T cells produce TNF, IL-1 $\beta$, and soluble interleukin-1 receptor antagonist (sIL-1Ra; Scanu et al., 2008). MP derived from $\mathrm{T}$ cells and monocytes also induce NF-кB-dependent expression of matrix metalloproteinases (MMP; Distler et al., 2005b), as well as some pro-inflammatory cytokines and chemokines such as IL-6, IL-8, macrophage chemoattractant protein (MCP)-1, MCP-2, and regulated upon activation, normal $\mathrm{T}$ cell expressed and secreted (RANTES) in synovial fibroblasts (Berckmans et al., 2005; Distler et al., 2005b). Monocyte/macrophage-derived MP also upregulate inflammatory mediator synthesis by epithelial cells (Cerri et al., 2006).

Not surprisingly, under certain conditions MP can also induce anti-inflammatory IL-10 expression in monocytes (Köppler et al., 2006) and transforming growth factor $\beta 1$ (TGF- $\beta 1$ ) in macrophages (Sadallah et al., 2011a). In some cases, MP can even be pro-apoptotic, especially in macrophages, which can undergo apoptosis upon uptake (Distler et al., 2005a; Huber et al., 2007). This activity presumably is due to differences in the source of MP. For example, neutrophil-derived MP specifically upregulate the expression of TGF- $\beta 1$, which helps to suppress the inflammatory response (Distler et al., 2005a; Huber et al., 2007). The MP used in these models induce macrophage apoptosis, possibly because the MP were generated from apoptotic cells, which might have transferred the apoptotic signals to the macrophages (Böing et al., 2008). This is similar to the behavior of macrophages to dampen inflammation after ingesting apoptotic bodies, to prevent over-reaction (Savill et al., 2002). However, these studies did not use pathogens and macrophages activated by Plasmodium were in contrast highly pro-inflammatory (Couper et al., 2010).

On the other hand, MP might contain factors induced or expressed by the infecting organism that could impede or abrogate the early induction of an effective immune response. For example, Influenza A NS1 protein expressed intracellularly has the capacity to suppress IFN-I production and inhibit apoptosis to enable better viral replication (Pauli et al., 2008; Wang et al., 2010). Similarly, several flavivirus subunits interfere with IFNsignaling at various levels and in different ways (reviewed in Daffis et al., 2009; Suthar et al., 2009). Such molecules, carried into cells yet to be infected could arguably give the infecting organism a survival advantage, enabling greater levels of replication in the 


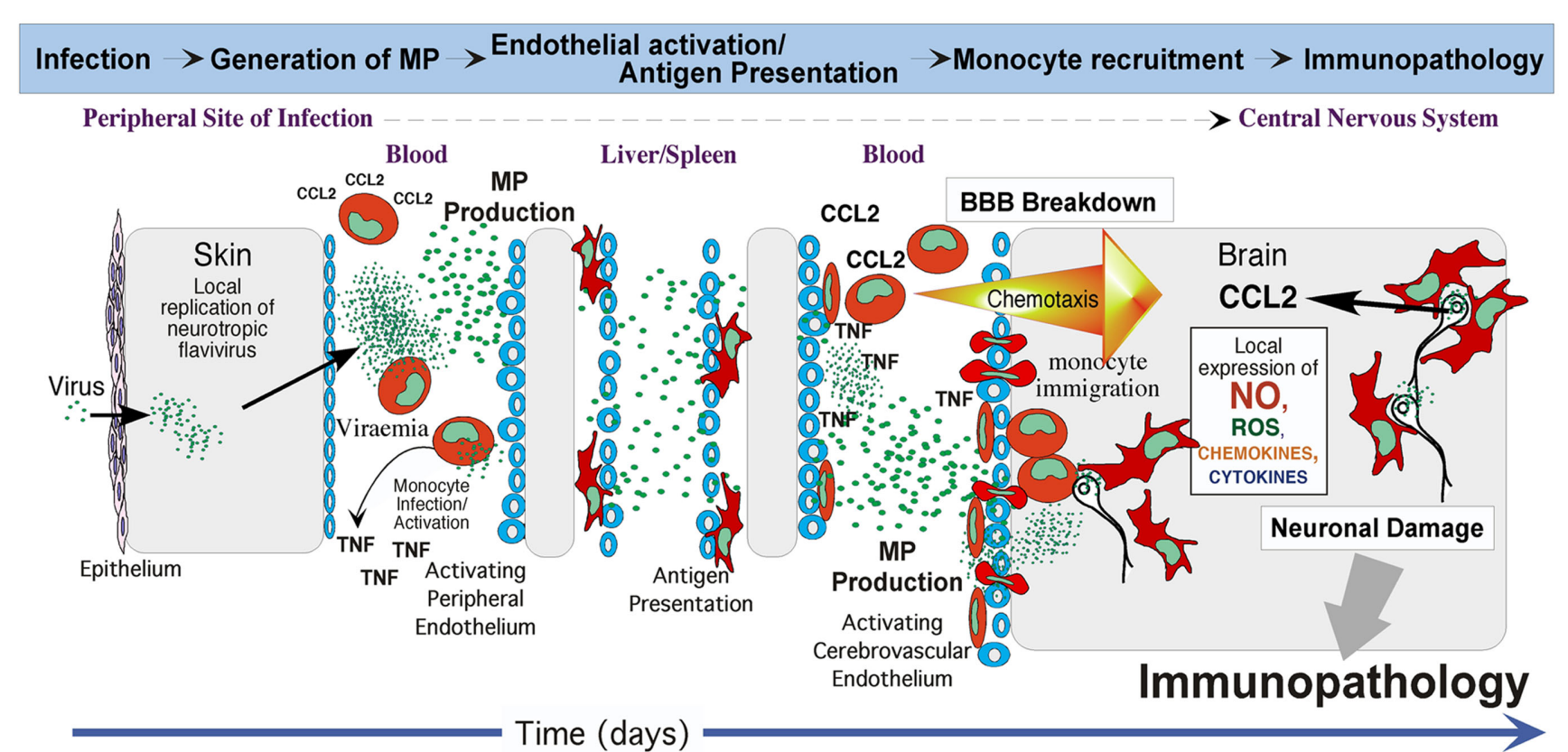

FIGURE 1 | Putative role of MP in immunopathogenesis of

flavivirus encephalitis. After local replication of virus at the site of infection, the ensuing viremia results in endothelial and monocyte infection. MP produced as a result of infection and via the consequent TNF secretion, are transported in the blood stream. On the one hand, MP from TNF-activated endothelium could further activate uninfected monocytes and endothelium at remote sites, such as in the brain, while MP from infected cells could carry viral antigen and activation signals to liver and spleen. Early antigen

presentation would likely advantage the host by generating anti-viral immune responses. On the other hand, endothelial activation may enable increased migration of monocytes into the brain in response to CCL2 secreted from infected neurons. While this immigration may initially enable early viral clearance, over-exuberant immigration of activated monocytes that differentiate into macrophages may be immunopathological for neurons via toxic soluble factors produced. This does not exclude a possible "Trojan horse" scenario, in which virus may also further gain access to the brain via the cerebral endothelium and/or via infected immigrant monocytes during encephalitis. host for longer periods of time, thus increasing the probability of transmission to vectors and/or to the next host. In the case of arboviruses, considering the relatively short times that organisms spend in the blood stream, even small increases in concentration and time spent in the blood stream could potentially subtend a significant survival advantage.

\section{IMPACT ON DISEASE}

The inflammatory conditions created by MP could in principle play important roles in controlling infection and pathogen clearance. How crucial these roles are in the immune system remain unclear, but as one of many factors that regulate the immune response against invading pathogens, MP could significantly influence the outcome for the host, both during the initial "knockdown" phase of controlling pathogen and in the ongoing adaptive response to it. Pro-inflammatory cytokines induced by MP would act to manage and contain the infection, while chemoattractant proteins would send signals to recruit leukocytes to the site of infection to eliminate the pathogen. Indeed, a further interesting characteristic of MP is their ability to upregulate adhesion molecules such as intercellular adhesion molecule-1 (ICAM-I; Berckmans et al., 2005) in target cells and promote monocyte recruitment (Mause et al., 2005). Along with ability of MP to induce MMP expression and TNF release, the endothelium becomes more permeable for immune active proteins and leukocytes to access the site of infection. Although this is an important step to enable pathogen clearance, it can be a double-edged sword in certain infectious diseases. In cases of lethal flavivirus encephalitis, in which immunopathology is one of the prominent features of pathogenesis, excessive monocyte infiltration of the central nervous system (CNS), and the accompanying pro-inflammatory cytokine spike are a major cause of mortality (King et al., 2007; Getts et al., 2008). We hypothesize that during viremia preceding encephalitis, flavivirus infecting endothelium, and blood monocytes induce MP, both as a consequence of infection and via TNF released by infected cells (Cheng et al., 2004). TNF independently enhances breakdown of the blood-brain barrier, potentially enabling virus access to the CNS (Wang et al., 2004). MP from TNF-activated endothelium could further activate uninfected monocytes and endothelium, while MP from infected cells could carry viral antigen, as well as activation signals to the liver and spleen. Early antigen presentation would likely advantage the host in generating anti-viral immune responses. However, WNVinfected CNS neurons recruit activated $\left(\mathrm{CCR} 2^{+}\right)$monocytes from the bone marrow to the brain via CCL2 (Getts et al., 2008). Here, TNF- and MP-mediated activation of CNS endothelium would facilitate macrophage margination, adhesion, and diapedesis in response to the chemokine gradient, thus potentially increasing numbers of monocytes recruited to the brain and exacerbating immunopathology (Figure 1).

Exaggerated immune responses also compromise the integrity of the blood-brain barrier in cerebral malaria via monocyte, TNF, 
and MP activities (Combes et al., 2010). Moreover, in mice deficient in the floppase, ATP-binding cassette transporter A1, which modulates PS distribution on the outer plasma membrane leaflet, MP production is reduced in cerebral malaria, abrogating neurological signs in this model, and presenting the possibility for pharmacological modulation of MP to ameliorate immunopathology (Combes et al., 2005; Penet et al., 2008).

Immunological aspects aside, MP could potentially also be used directly as transport by viruses, including flavivirus, Influenza, and herpes simplex virus (HSV) that propagate via a process of ectocytosis from the plasma membrane of an infected cell. In a model of HIV-1, the glycome profile and the budding signal of the virion were similar to that of the MP secreted in conjunction, suggesting that the mechanism for viral propagation was similar to that of the formation of MP (Krishnamoorthy et al., 2009; Gan and Gould, 2011). Even if MP formation selectively excludes budding virions, the MP may still potentially contain unpackaged viral genome and other viral proteins necessary for replication in the target cell. In either scenario, MP may be used by viruses as "Trojan Horses" to spread to other cells. Indeed, HIV-1 induces MP that "express" CD45, CD80, CD86, as well as MHC-I and II (Esser et al., 2001), thus, potentially masking themselves as being of "host" origin. In addition, HIV also induces CCR5-containing MP and can transfer this receptor to other peripheral blood mononuclear cells (PBMC) deficient of endogenous CCR5, enabling infection of these cells (Mack et al., 2000). However, the success of allogeneic transplantation of $\Delta 32 / \Delta 32$ CCR5 stem cells in keeping the patient HIV free, indicates that much more remains to be understood about these processes (Hütter et al., 2009).

In conclusion, the study of MP is an exciting emerging field. As with all emerging areas, a number of technical issues remain to be

\section{REFERENCES}

Abdel-Monem, H., Dasgupta, S. K., Le, A., Prakasam, A., and Thiagarajan, P. (2010). Phagocytosis of platelet microvesicles and beta2glycoprotein I. Thromb. Haemost. 104, 335-341.

Aharon, A., Tamari, T., and Brenner, B. (2008). Monocyte-derived microparticles and exosomes induce procoagulant and apoptotic effects on endothelial cells. Thromb. Haemost. 100, 878-885.

Aline, F., Bout, D., Amigorena, S., Roingeard, P., and Dimier-Poisson, I. (2004). Toxoplasma gondii antigenpulsed-dendritic cell-derived exosomes induce a protective immune response against $T$. gondii infection. Infect. Immun. 72, 4127-4137.

Aliotta, J. M., Pereira, M., Johnson, K. W., De Paz, N., Dooner, M. S., Puente, N., Ayala, C., Brilliant, K., Berz, D., Lee, D., Ramratnam, B., Mcmillan, P. N., Hixson, D. C., Josic, D., and Quesenberry, P. J. (2010). Microvesicle entry into marrow cells mediates tissue-specific changes in mRNA by direct delivery of mRNA

fully resolved. For example, the accurate determination of MP size and phenotype, their clear distinction from and relationship to, other membrane vesicles, and their pure separation for functional experimental purposes, remain a significant challenge (György et al., 2011). While MP clearly have likely roles in homeostasis and inflammation, few studies have to date directly addressed their involvement in infectious disease. Thus, many questions remain to be answered, perhaps most important among which are, whether the production of MP as a programmatic response to infection confers an overall species survival advantage. At the mechanistic level, also, how cellular decision-making occurs to produce MP, what they should contain, and whether production of the full range of membranous vesicles is required and/or produced kinetically to accommodate host requirements from initial infection to disease resolution, remains to be elucidated. As with most defenses against invading pathogens, on the one hand, the transfer of phenotype and function by MP may be of considerable benefit to the host, in the early warning and initiating of immune defenses at both innate and adaptive levels. On the other, however, this may exacerbate immune responses leading to immune pathology, or be commandeered by the invading pathogen for its own survival.

\section{ACKNOWLEDGMENTS}

This work was supported by an Australian Postgraduate Award to Zheng Lung Ling. In addition, funding was awarded by National Health and Medical Research Project Grants 571014, to Georges E. Grau and Valery Combes, and 512413, to Nicholas J. C. King, and by Australian Research Council Discovery Grant 0774425, to Georges E. Grau and Valery Combes, as well as USYD Bridging Grants \# 2009-02563 and \# 2009-02600 to GEG and VC, and \# 2009-02576 to Nicholas J. C. King.

Tumour-derived microvesicles carry several surface determinants and mRNA of tumour cells and transfer some of these determinants to monocytes. Cancer Immunol. Immunother. 55, 808-818.

Berckmans, R. J., Nieuwland, R., Kraan, M. C., Schaap, M. C., Pots, D., Smeets, T. J., Sturk, A., and Tak, P. P. (2005). Synovial microparticles from arthritic patients modulate chemokine and cytokine release by synoviocytes. Arthritis Res. Ther. 7, R536-R544.

Bernimoulin, M., Waters, E. K., Foy, M., Steele, B. M., Sullivan, M., Falet, H., Walsh, M. T., Barteneva, N., Geng, J. G., Hartwig, J. H., Maguire, P. B., and Wagner, D. D. (2009). Differential stimulation of monocytic cells results in distinct populations of microparticles. J. Thromb. Haemost. 7, 1019-1028.

Böing, A. N., Hau, C. M., Sturk, A., and Nieuwland, R. (2008). Platelet microparticles contain active caspase 3. Platelets 19, 96-103.

Cerri, C., Chimenti, D., Conti, I., Neri, T., Paggiaro, P., and Celi, A.
(2006). Monocyte/macrophagederived microparticles up-regulate inflammatory mediator synthesis by human airway epithelial cells. J. Immunol. 177, 1975-1980.

Chaudhri, G., Quah, B. J., Wang, Y., Tan, A. H., Zhou, J., Karupiah, G., and Parish, C. R. (2009). T cell receptor sharing by cytotoxic T lymphocytes facilitates efficient virus control. Proc. Natl. Acad. Sci. U.S.A. 106, 14984-14989.

Cheng, Y., King, N. J., and Kesson, A. M. (2004). The role of tumor necrosis factor in modulating responses of murine embryo fibroblasts by flavivirus, West Nile. Virology 329, 361-370.

Climent, N., Guerra, S., García, F., Rovira, C., Miralles, L., Gómez, C. E., Piqué, N., Gil, C., Gatell, J. M., Esteban, M., and Gallart, T. (2011). Dendritic cells exposed to MVAbased HIV-1 vaccine induce highly functional HIV-1-specific CD8(+) $\mathrm{T}$ cell responses in HIV-1-infected individuals. PLoS ONE 6, e19644. doi:10.1371/journal.pone.0019644 
Cocucci, E., Racchetti, G., and Meldolesi, J. (2009). Shedding microvesicles: artefacts no more. Trends Cell Biol. 19, 43-51.

Coltel, N., Combes, V., Wassmer, S. C., Chimini, G., and Grau, G. E. (2006). Cell vesiculation and immunopathology: implications in cerebral malaria. Microbes Infect. 8, 2305-2316.

Combes, V., Coltel, N., Alibert, M., Van Eck, M., Raymond, C., Juhan-Vague, I., Grau, G. E., and Chimini, G. (2005). ABCAl gene deletion protects against cerebral malaria: potential pathogenic role of microparticles in neuropathology. Am. J. Pathol. 166, 295-302.

Combes, V., El-Assaad, F., Faille, D., Jambou, R., Hunt, N. H., and Grau, G. E. (2010). Microvesiculation and cell interactions at the brain-endothelial interface in cerebral malaria pathogenesis. Prog. Neurobiol. 91, 140-151.

Combes, V., Simon, A. C., Grau, G. E., Arnoux, D., Camoin, L., Sabatier, F., Mutin, M., Sanmarco, M., Sampol, J., and Dignat-George, F. (1999). In vitro generation of endothelial microparticles and possible prothrombotic activity in patients with lupus anticoagulant. J. Clin. Invest. 104, 93-102.

Combes, V., Taylor, T. E., JuhanVague, I., Mège, J. L., Mwenechanya, J., Tembo, M., Grau, G. E., and Molyneux, M. E. (2004). Circulating endothelial microparticles in malawian children with severe falciparum malaria complicated with coma. JAMA 291, 2542-2544.

Couper, K. N., Barnes, T., Hafalla, J. C., Combes, V., Ryffel, B., Secher, T., Grau, G. E., Riley, E. M., and De Souza, J. B. (2010). Parasitederived plasma microparticles contribute significantly to malaria infection-induced inflammation through potent macrophage stimulation. PLoS Pathog. 6, e1000744. doi:10.1371/journal.ppat.1000744

Creagh, E. M., and O’Neill, L. A. (2006). TLRs, NLRs and RLRs: a trinity of pathogen sensors that co-operate in innate immunity. Trends Immunol. 27, 352-357.

Daffis, S., Suthar, M. S., Gale, M. Jr., and Diamond, M. S. (2009). Measure and countermeasure: type I IFN (IFN-alpha/beta) antiviral response against West Nile virus. J. Innate Immun. 1, 435-445.

Dasgupta, S. K., Abdel-Monem, H., Niravath, P., Le, A., Bellera, R. V., Langlois, K., Nagata, S., Rumbaut, R. E., and Thiagarajan, P. (2009). Lactadherin and clearance of plateletderived microvesicles. Blood 113, 1332-1339.
De Maio, A. (2011). Extracellular heat shock proteins, cellular export vesicles, and the Stress Observation System: a form of communication during injury, infection, and cell damage. It is never known how far a controversial finding will go! Dedicated to Ferruccio Ritossa. Cell Stress Chaperones 16, 235-249.

De Rop, C., Stadler, M., Buchholz, S., Eisert, R., Ganser, A., and Trummer, A. (2011). Evaluation of tissue factor bearing microparticles as biomarkers in allogeneic stem-cell transplantation. Transplantation 92, 351-358.

Dean, W. L., Lee, M. J., Cummins, T. D., Schultz, D. J., and Powell, D. W. (2009). Proteomic and functional characterisation of platelet microparticle size classes. Thromb. Haemost. 102, 711-718.

Del Conde, I., Shrimpton, C. N., Thiagarajan, P., and López, J. A. (2005). Tissue-factor-bearing microvesicles arise from lipid rafts and fuse with activated platelets to initiate coagulation. Blood 106, 1604-1611.

Denzer, K., Kleijmeer, M. J., Heijnen, H. F., Stoorvogel, W., and Geuze, H. J. (2000). Exosome: from internal vesicle of the multivesicular body to intercellular signaling device. J. Cell. Sci. 113(Pt 19), 3365-3374.

Distler, J. H., Huber, L. C., Hueber, A. J., Reich, C. F. III, Gay, S., Distler, O., and Pisetsky, D. S. (2005a). The release of microparticles by apoptotic cells and their effects on macrophages. Apoptosis 10, 731-741.

Distler, J. H., Jüngel, A., Huber, L. C., Seemayer, C. A., Reich, C. F. III, Gay, R. E., Michel, B. A., Fontana, A., Gay, S., Pisetsky, D. S., and Distler, O. (2005b). The induction of matrix metalloproteinase and cytokine expression in synovial fibroblasts stimulated with immune cell microparticles. Proc. Natl. Acad. Sci. U.S.A. 102, 2892-2897.

Esser, M. T., Graham, D. R., Coren, L. V., Trubey, C. M., Bess, J. W. Jr., Arthur, L. O., Ott, D. E., and Lifson, J. D. (2001). Differential incorporation of CD45, CD80 (B7-1), CD86 (B7-2), and major histocompatibility complex class I and II molecules into human immunodeficiency virus type 1 virions and microvesicles: implications for viral pathogenesis and immune regulation. J. Virol. 75, 6173-6182.

Faille, D., Combes, V., Mitchell, A. J., Fontaine, A., Juhan-Vague, I., Alessi, M. C., Chimini, G., Fusaï, T., and Grau, G. E. (2009). Platelet microparticles: a new player in malaria parasite cytoadherence to human brain endothelium. FASEB J. 23, 3449-3458.

Fritzsching, B., Schwer, B., Kartenbeck, J., Pedal, A., Horejsi, V., and Ott, M. (2002). Release and intercellular transfer of cell surface CD81 via microparticles. J. Immunol. 169, 5531-5537.

Gan, X., and Gould, S. J. (2011). Identification of an inhibitory budding signal that blocks the release of HIV particles and exosome/microvesicle proteins. Mol. Biol. Cell 22, 817-830.

Garcia, B. A., Smalley, D. M., Cho, H. Shabanowitz, J., Ley, K., and Hunt, D. F. (2005). The platelet microparticle proteome. J. Proteome Res. 4, 1516-1521.

Gasser, O., and Schifferli, J. A. (2004). Activated polymorphonuclear neutrophils disseminate antiinflammatory microparticles by ectocytosis. Blood 104, 2543-2548.

Geisbert, T. W., Young, H. A., Jahrling, P. B., Davis, K. J., Kagan, E., and Hensley, L. E. (2003). Mechanisms underlying coagulation abnormalities in ebola hemorrhagic fever: overexpression of tissue factor in primate monocytes/macrophages is a key event. J. Infect. Dis. 188 , 1618-1629.

Getts, D. R., Terry, R. L., Getts, M. T., Müller, M., Rana, S., Shrestha, B. Radford, J., Van Rooijen, N., Campbell, I. L., and King, N. J. (2008). Ly6c+ "inflammatory monocytes" are microglial precursors recruited in a pathogenic manner in West Nile virus encephalitis. J. Exp. Med. 205, 2319-2337.

György, B., Szabó, T. G., Pásztoí, M., Pál, Z., Misjak, P., Aradi, B., László, V., Pállinger, E., Pap, E., Kittel, A., Nagy, G., Falus, A., and Buzás, E. I. (2011) Membrane vesicles, current state-ofthe-art: emerging role of extracellular vesicles. Cell. Mol. Life Sci. 68, 2667-2688.

Huber, L. C., Jüngel, A., Distler, J. H., Moritz, F., Gay, R. E., Michel, B. A., Pisetsky, D. S., Gay, S., and Distler, O. (2007). The role of membrane lipids in the induction of macrophage apoptosis by microparticles. Apoptosis 12, 363-374.

Hütter, G., Nowak, D., Mossner, M. Ganepola, S., Müssig, A., Allers, K., Schneider, T., Hofmann, J., Kücherer, C., Blau, O., Blau, I. W., Hofmann, W. K., and Thiel, E. (2009). Long-term control of HIV by CCR5 Delta32/Delta32 stem-cell transplantation. N. Engl. J. Med.360, 692-698.

Kim, S. H., Bianco, N. R., Shufesky, W. J., Morelli, A. E., and Robbins, P. D. (2007). MHC class II+ exosomes in plasma suppress inflammation in an antigen-specific and Fas ligand/
Fas-dependent manner. J. Immunol. 179, 2235-2241.

King, N. J., Getts, D. R., Getts, M. T., Rana, S., Shrestha, B., and Kesson, A. M. (2007). Immunopathology of flavivirus infections. Immunol. Cell Biol. 85, 33-42.

Köppler, B., Cohen, C., Schlöndorff, D., and Mack, M. (2006). Differential mechanisms of microparticle transfer to B cells and monocytes: anti-inflammatory propertiesof microparticles. Eur. J. Immunol. 36, 648-660.

Krishnamoorthy, L., Bess, J. W. Jr., Preston, A. B., Nagashima, K., and Mahal, L. K. (2009). HIV-1 and microvesicles from $\mathrm{T}$ cells share a common glycome, arguing for a common origin. Nat. Chem. Biol. 5 , 244-250.

Li, G., Zhang, J., Tong, X., Liu, W., and Ye, X. (2011). Heat shock protein 70 inhibits the activity of influenza a virus ribonucleoprotein and blocks the replication of virus in vitro and in vivo. PLoS ONE 6, e16546. doi:10.1371/journal.pone.0016546

Mack, M., Kleinschmidt, A., Brühl, H., Klier, C., Nelson, P. J., Cihak, J., Plachý, J., Stangassinger, M., Erfle, V., and Schlöndorff, D. (2000). Transfer of the chemokine receptor CCR5 between cells by membrane-derived microparticles: a mechanism for cellular human immunodeficiency virus 1 infection. Nat. Med. 6, 769-775.

Mackenzie, A., Wilson, H. L., KissToth, E., Dower, S. K., North, R. A., and Surprenant, A. (2001). Rapid secretion of interleukin-1beta by microvesicle shedding. Immunity 15, 825-835.

Martin, S., Tesse, A., Hugel, B., Martínez, M. C., Morel, O., Freyssinet, J. M. and Andriantsitohaina, R. (2004). Shed membrane particles from $\mathrm{T}$ lymphocytes impair endothelial function and regulate endothelial protein expression. Circulation 109, 1653-1659.

Mause, S. F., Von Hundelshausen, P., Zernecke, A., Koenen, R. R., and Weber, C. (2005). Platelet microparticles: a transcellular delivery system for RANTES promoting monocyte recruitment on endothelium. Arterioscler. Thromb. Vasc. Biol. 25, 1512-1518.

Mause, S. F., and Weber, C. (2010). Microparticles: protagonists of a novel communication network for intercellular information exchange. Circ. Res. 107, 1047-1057.

Medzhitov, R., and Horng, T. (2009). Transcriptional control of the inflammatory response. Nat. Rev. Immunol. 9, 692-703. 
Mostefai, H. A., Meziani, F., Mastronardi, M. L., Agouni, A., Heymes, C., Sargentini, C., Asfar, P., Martínez, M. C., and Andriantsitohaina, R. (2008). Circulating microparticles from patients with septic shock exert protective role in vascular function. Am. J. Respir. Crit. Care Med. 178, 1148-1155.

Nieuwland, R., Berckmans, R. J., Mcgregor, S., Böing, A. N., Romijn, F. P., Westendorp, R. G., Hack, C. E., and Sturk, A. (2000). Cellular origin and procoagulant properties of microparticles in meningococcal sepsis. Blood 95, 930-935.

Obregon, C., Rothen-Rutishauser, B., Gerber, P., Gehr, P., and Nicod, L. P. (2009). Active uptake of dendritic cell-derived exovesicles by epithelial cells induces the release of inflammatory mediators through a TNF-alpha-mediated pathway. Am. J. Pathol. 175, 696-705.

Obregon, C., Rothen-Rutishauser, B., Gitahi, S. K., Gehr, P., and Nicod, L. P. (2006). Exovesicles from human activated dendritic cells fuse with resting dendritic cells, allowing them to present alloantigens. Am. J. Pathol. 169, 2127-2136.

Ohiro, Y., Usheva, A., Kobayashi, S., Duffy, S. L., Nantz, R., Gius, D., and Horikoshi, N. (2003). Inhibition of stress-inducible kinase pathways by tumorigenic mutant p53. Mol. Cell. Biol. 23, 322-334.

Owens, A. P. III, and Mackman, N. (2011). Microparticles in hemostasis and thrombosis. Circ. Res. 108, 1284-1297.

Pankoui Mfonkeu, J. B., Gouado, I., Fotso Kuaté, H., Zambou, O., Amvam Zollo, P. H., Grau, G. E., and Combes, V. (2010). Elevated cell-specific microparticles are a biological marker for cerebral dysfunctions in human severe malaria. PLoS ONE 5, e13415. doi:10.1371/journal.pone.0013415

Pap, E., Pállinger, E., Pásztói, M., and Falus, A. (2009). Highlights of a new type of intercellular communication: microvesicle-based information transfer. Inflamm. Res. 58, 1-8.

Pauli, E. K., Schmolke, M., Wolff, T., Viemann, D., Roth, J., Bode, J. G., and Ludwig, S. (2008). Influenza A virus inhibits type I IFN signaling via NF-kappaB-dependent induction of SOCS-3 expression. PLoS Pathog. 4, e1000196. doi:10.1371/journal.ppat.1000196

Penet, M. F., Abou-Hamdan, M., Coltel, N., Cornille, E., Grau, G. E., De
Reggi, M., and Gharib, B. (2008). Protection against cerebral malaria by the low-molecular-weight thiol pantethine. Proc. Natl. Acad. Sci. U.S.A. 105, 1321-1326.

Piccin, A., Murphy, W. G., and Smith, O. P. (2007). Circulating microparticles: pathophysiology and clinical implications. Blood Rev. 21, 157-171.

Pizzirani, C., Ferrari, D., Chiozzi, P., Adinolfi, E., Sandonà, D., Savaglio, E., and Di Virgilio, F. (2007). Stimulation of $\mathrm{P} 2$ receptors causes release of IL-1beta-loaded microvesicles from human dendritic cells. Blood 109, 3856-3864

Quast, T., Eppler, F., Semmling, V., Schild, C., Homsi, Y., Levy, S., Lang, T., Kurts, C., and Kolanus, W. (2011). CD81 is essential for the formation of membrane protrusions and regulates Racl-activation in adhesiondependent immune cell migration. Blood 118, 1818-1827.

Ramachandra, L., Qu, Y., Wang, Y., Lewis, C. J., Cobb, B. A., Takatsu, K., Boom, W. H., Dubyak, G. R., and Harding, C. V. (2010). Mycobacterium tuberculosis synergizes with ATP to induce release of microvesicles and exosomes containing major histocompatibility complex class II molecules capable of antigen presentation. Infect. Immun. 78, 5116-5125.

Ratajczak, J., Wysoczynski, M., Hayek, F., Janowska-Wieczorek, A., and Ratajczak, M. Z. (2006). Membranederived microvesicles: important and underappreciated mediators of cell-to-cell communication. Leukemia 20, 1487-1495.

Rawat, P., and Mitra, D. (2011). Cellular heat shock factor 1 positively regulates human immunodeficiency virus-1 gene expression and replication by two distinct pathways. Nucleic Acids Res. 39, 5879-5892.

Razorenova, O. V., Agapova, L. S., Budanov, A. V., Ivanov, A. V., Strunina, S. M., and Chumakov, P. M. (2005). Retroviral reporter systems for the assessment of activity of stress-induced signal transduction pathways controlled by p53, HIF-1 and HSF-1 transcription factors. Mol. Biol. (Mosk.) 39, 286-293.

Sadallah, S., Eken, C., Martin, P. J., and Schifferli, J. A. (2011a). Microparticles (ectosomes) shed by stored human platelets downregulate macrophages and modify the development of dendritic cells. J. Immunol. 186, 6543-6552.
Sadallah, S., Eken, C., and Schifferli, J. A. (2011b). Ectosomes as immunomodulators. Semin. Immunopathol. 33, 487-495.

Satta, N., Toti, F., Feugeas, O., Bohbot, A., Dachary-Prigent, J., Eschwège, V., Hedman, H., and Freyssinet, J. M. (1994). Monocyte vesiculation is a possible mechanism for dissemination of membrane-associated procoagulant activities and adhesion molecules after stimulation by lipopolysaccharide. J. Immunol. 153 , 3245-3255.

Savill, J., Dransfield, I., Gregory, C., and Haslett, C. (2002). A blast from the past: clearance of apoptotic cells regulates immune responses. Nat. Rev. Immunol. 2, 965-975.

Scanu, A., Molnarfi, N., Brandt, K. J., Gruaz, L., Dayer, J. M., and Burger, D. (2008). Stimulated T cells generate microparticles, which mimic cellular contact activation of human monocytes: differential regulation of pro- and anti-inflammatory cytokine production by high-density lipoproteins. J. Leukoc. Biol. 83, 921-927.

Schorey, J. S., and Bhatnagar, S. (2008). Exosome function: from tumor immunology to pathogen biology. Traffic 9, 871-881.

Seth, R. B., Sun, L., and Chen, Z. J. (2006). Antiviral innate immunity pathways. Cell Res. 16, 141-147.

Sheremata, W. A., Jy, W., Delgado, S., Minagar, A., Mclarty, J., and Ahn, Y. (2006). Interferon-betala reduces plasma $\mathrm{CD} 31+$ endothelial microparticles (CD31+EMP) in multiple sclerosis. J. Neuroinflammation 3, 23.

Smalley, D. M., Sheman, N. E., Nelson, K., and Theodorescu, D. (2008). Isolation and identification of potential urinary microparticle biomarkers of bladder cancer. J. Proteome Res. 7, 2088-2096.

Sprague, D. L., Elzey, B. D., Crist, S. A., Waldschmidt, T. J., Jensen, R. J., and Ratliff, T. L. (2008). Platelet-mediated modulation of adaptive immunity: unique delivery of CD154 signal by plateletderived membrane vesicles. Blood 111, 5028-5036.

Stern-Ginossar, N., and Mandelboim, O. (2009). An integrated view of the regulation of NKG2D ligands. Immunology 128, 1-6.

Suthar, M. S., Gale, M. Jr., and Owen, D. M. (2009). Evasion and disruption of innate immune signalling by hepatitis $\mathrm{C}$ and West Nile viruses. Cell Microbiol. 11, 880-888.
Tesse, A., Martínez, M. C., Hugel, B., Chalupsky, K., Muller, C. D., Meziani, F., Mitolo-Chieppa, D., Freyssinet, J. M., and Andriantsitohaina, R. (2005). Upregulation of proinflammatory proteins through NF-kappaB pathway by shed membrane microparticles results in vascular hyporeactivity. Arterioscler. Thromb. Vasc. Biol. 25, 2522-2527.

Théry, C., Ostrowski, M., and Segura, E. (2009). Membrane vesicles as conveyors of immune responses. Nat. Rev. Immunol. 9, 581-593.

Thompson, A. J., and Locarnini, S. A. (2007). Toll-like receptors, RIG-Ilike RNA helicases and the antiviral innate immune response. Immunol. Cell Biol. 85, 435-445.

Wang, J. G., Manly, D., Kirchhofer, D., Pawlinski, R., and Mackman, N. (2009). Levels of microparticle tissue factor activity correlate with coagulation activation in endotoxemic mice. J. Thromb. Haemost. 7, 1092-1098.

Wang, T., Town, T., Alexopoulou, L., Anderson, J. F., Fikrig, E., and Flavell, R. A. (2004). Toll-like receptor 3 mediates West Nile virus entry into the brain causing lethal encephalitis. Nat. Med. 10, 1366-1373.

Wang, X., Shen, Y., Qiu, Y., Shi, Z., Shao, D., Chen, P., Tong, G., and Ma, Z. (2010). The non-structural (NS1) protein of influenza A virus associates with p53 and inhibits p53-mediated transcriptional activity and apoptosis. Biochem. Biophys. Res. Commun. 395, 141-145.

Yuan, A., Farber, E. L., Rapoport, A. L., Tejada, D., Deniskin, R., Akhmedov, N. B., and Farber, D. B. (2009). Transfer of microRNAs by embryonic stem cell microvesicles. PLoS ONE 4, e4722. doi:10.1371/journal.pone.0004722

Zhang, C., Yang, Y., Zhou, X., Yang, Z., Liu, X., Cao, Z., Song, H., He, Y., and Huang, P. (2011). The NS1 protein of influenza a virus interacts with heat shock protein Hsp90 in human alveolar basal epithelial cells: implication for virus-induced apoptosis. Virol. J. 8, 181 .

Zinkernagel, A. S., Johnson, R. S., and Nizet, V. (2007). Hypoxia inducible factor (HIF) function in innate immunity and infection. J. Mol. Med. 85, 1339-1346.

Zubairova, L. D., Zubairov, D. M., Andrushko, I. A., Svintenok, G. Y., and Mustafin, I. G. (2006). Cell microvesicles during experimental endotoxemia. Bull. Exp. Biol. Med. $142,573-576$. 
Zwicker, J. I., Trenor, C. C. III, Furie, B. C., and Furie, B. (2011). Tissue factor-bearing microparticles and thrombus formation. Arterioscler. Thromb. Vasc. Biol. 31, 728-733.

Conflict of Interest Statement: The authors declare that the research was conducted in the absence of any commercial or financial relationships that could be construed as a potential conflict of interest.

Received: 06 September 2011; accepted: 11 November 2011; published online: 29 November 2011.
Citation: Ling ZL, Combes V, Grau GE and King NJC (2011) Microparticles as immune regulators in infectious disease an opinion. Front. Immun. 2:67. doi 10.3389/fimmu.2011.00067

This article was submitted to Frontiers in Microbial Immunology, a specialty of Frontiers in Immunology.
Copyright $\odot 2011$ Ling, Combes, Grau and King. This is an open-access article distributed under the terms of the Creative Commons Attribution Non Commercial License, which permits noncommercial use, distribution, and reproduction in other forums, provided the original authors and source are credited. 